\title{
Dabrafenib in an elderly patient with metastatic melanoma and BRAF V600R mutation: a case report
}

\author{
David Casadevall1, ${ }^{1 *}$, Joana Vidal ${ }^{1,5}$, Fernando Gallardo ${ }^{2}$, Flavio Zuccarino ${ }^{3}$, Montserrat Arumí-Uría ${ }^{4,5}$, \\ Alba Dalmases ${ }^{4,5}$, Beatriz Bellosillo $0^{4,5}$ and Clara Montagut ${ }^{1,5}$
}

\begin{abstract}
Background: Approximately $50 \%$ of malignant melanomas harbor activating point mutations in the BRAF gene. Typically, these mutations result in the substitution of the amino acid valine at codon 600 of the gene, and 90-95 $\%$ of mutations are either $B R A F^{\mathrm{V} 600 \mathrm{E}}$ or $B R A F^{\mathrm{V} 600 \mathrm{~K}}$. Specific BRAF inhibitors such as dabrafenib and vemurafenib are the mainstays of treatment in patients with metastatic BRAF-mutant malignant melanomas. The third most common BRAF mutation is V600R, which also leads to increased BRAF signaling. Although evidence exists about the activity of dabrafenib and vemurafenib in patients with the $B R A F^{V 600 R}$ mutation, these patients have been systematically excluded from recent trials with targeted therapies.

Case presentation: Here, we report the positive results in terms of survival and quality of life obtained with dabrafenib in an 80-year-old Caucasian male patient with a Charlson Comorbidity Index of 8 diagnosed with metastatic malignant melanoma harboring the $B R A F^{V 600 R}$ mutation. Our patient was treated with dabrafenib for 7 months with minimal toxicity. We also report exploratory analyses of circulating tumor DNA during targeted treatment. Interestingly, the mutation was not detected after starting treatment and became detectable before radiological disease progression.

Conclusions: Our report suggests that (1) a relevant benefit can be obtained with a BRAF inhibitor in real-world patients with a malignant melanoma harboring a BRAF ${ }^{V 600 R}$ mutation, and that (2) circulating tumor DNA detection might be of help in assessing tumor burden in everyday clinical practice. The results reported here should encourage the inclusion of patients with $B R A F^{\mathrm{V} 600 \mathrm{R}}$-mutated malignant melanomas in future prospective clinical trials with BRAF inhibitors.
\end{abstract}

Keywords: Melanoma, BRAF, V600R, Dabrafenib, ctDNA

\section{Background}

The $B R A F$ gene is localized at $7 \mathrm{q} 34$ and encodes a family of protein kinases involved in cell signal transduction through the mitogen-activated protein kinase MAPK (Ras/Raf/MEK/ERK) pathway, which mainly affects cell differentiation and proliferation [1-4]. Activation of the MAPK pathway, generally through point mutations in one or more of its components, has been associated with

\footnotetext{
* Correspondence: dcasadevall@parcdesalutmar.cat

${ }^{1}$ Medical Oncology Department, Hospital del Mar, Passeig Marítim 25-29, 08003 Barcelona, Spain

${ }^{5}$ Cancer Research Program, IMIM (Hospital del Mar Medical Research Institute), Barcelona, Spain

Full list of author information is available at the end of the article
}

several diseases, such as cardiofaciocutaneous syndrome, Erdheim-Chester disease, Langerhans cell histiocytosis, and Noonan syndrome [2-4]. BRAF mutations have also been associated with malignancies, such as melanoma, thyroid carcinoma, and colorectal carcinoma $[5,6]$.

Identification of BRAF as an actionable target in advanced malignant melanoma (MM) has led to a dramatic change in the treatment scope of this disease [7]. Approximately $50 \%$ of MMs harbor mutations in amino acid 600 of the $B R A F$ gene [5]. These are usually amino acid substitutions that result in a protein conformation change that leads to constitutionally elevated kinase activity [6]. Over $90 \%$ of activating mutations are either valine-glutamate $\left(B R A F^{\mathrm{V} 600 \mathrm{E}}\right)$ or valine-lysine $\left(B R A F^{\mathrm{V} 600 \mathrm{~K}}\right)$ substitutions, 
which account for 75 and $15 \%$, respectively [8]. Dabrafenib and vemurafenib were the first BRAF inhibitors to show a clear benefit over chemotherapy treatment in patients with $B R A F$-mutated metastatic MM $[9,10]$.

Although initially designed to target the $B R A F^{\mathrm{V} 600 \mathrm{E}} \mathrm{mu}-$ tation, early studies of dabrafenib and vemurafenib also included $B R A F^{\mathrm{V} 600 \mathrm{~K}}$-mutated melanoma cases, and showed a clinical benefit in this subset of patients $[7,11$, 12]. The third most frequent BRAF mutation is V600R, accounting for $1-5 \%$ depending on the series and sequencing technique $[8,13,14]$. Patients with this rare mutation were excluded from pivotal trials with BRAF inhibitors and have also been excluded from the more recent BRAF/ MEK dual inhibition trials $[15,16]$. However, activity of BRAF inhibitors in this context has been reported in $\mathrm{BRAF}^{\mathrm{V} 600 \mathrm{R}}$-mutated melanoma cell lines [17] and in a small Australian patient series [18].

Here, we present a case of durable clinical benefit with the use of dabrafenib in an 80-year-old patient with moderate comorbidity diagnosed with metastatic MM harboring the $B R A F^{\mathrm{V} 600 \mathrm{R}}$ mutation. Additionally, due to the emergence of circulating tumor (ct) DNA as a promising biomarker for assessing tumor burden and treatment response [19], we collected serial plasma samples and report exploratory analyses of ctDNA during our patient's treatment.

\section{Case presentation}

Our patient was an 80-year-old Caucasian man with a history of arterial hypertension, dyslipidemia, hyperuricemia, and hypothyroidism, for which he was being medically treated. He did not drink alcohol and was a former smoker of cigarettes. Our patient had no familiar history of cancer. He had undergone a right nephrectomy in 2002 due to a spontaneous retroperitoneal hematoma and consequently had chronic renal insufficiency (usual creatinine levels of $1.6-2.0 \mathrm{mg} / \mathrm{dL}$ and a glomerular filtration rate of $40 \mathrm{~mL} /$ $\mathrm{min})$. He had no history of cognitive impairment or dementia and retained full autonomy in his daily activities and personal care needs. In June 2010 he had undergone surgical resection of a $26 \mathrm{~mm}$-diameter pigmented lesion on his right pre-auricular region. The pathology report disclosed an ulcerated MM with a Breslow index of $0.7 \mathrm{~mm}$ and a Clark level of III (pT1b, Stage IB) [20].

\section{Clinical findings}

When first evaluated by our Oncology Department, our patient presented with moderate asthenia that limited his daily activity, without other relevant clinical symptoms. A physical examination did not detect any relevant findings (Eastern Cooperative Oncology Group [ECOG] performance status of 1). A full-body CT scan revealed the presence of pulmonary and hepatic nodules (Fig. 1a). No brain metastases were detected. A complete blood work-up produced the following results (normal range values in parenthesis): glucose $87 \mathrm{mg} / \mathrm{dL}$ (75-115), urea $70 \mathrm{mg} / \mathrm{dL}$ (10-50), serum creatinine $1.76 \mathrm{mg} / \mathrm{dL}(0.6-1.4)$, glomerular filtration rate $40 \mathrm{~mL} / \mathrm{min} / 1.73 \mathrm{~m}^{2}(>60)$, urate $7.4 \mathrm{mg} /$ dL (3.4-7.0), sodium $138 \mathrm{mmol} / \mathrm{L}$ (135-146), potassium $4.7 \mathrm{mmol} / \mathrm{L}$ (3.5-5.1), total bilirubin $0.43 \mathrm{mg} / \mathrm{dL}(0.2-1.2)$, aspartate aminotransferase (AST) $59 \mathrm{UI} / \mathrm{L}$ (10-38), alanine aminotransferase (ALT) $52 \mathrm{UI} / \mathrm{L}$ (7-41), gammaglutamyltransferase (GGT) 363 UI/L (8-61), alkaline phosphatase 204 UI/L (40-129), serum calcium $9 \mathrm{mg} / \mathrm{dL}$ (8.5-10.5), serum albumin $3.9 \mathrm{~g} / \mathrm{dL}$ (3.8-5.1), hemoglobin $12.1 \mathrm{~g} / \mathrm{dL}$ (13-17), total leukocyte count $10.1 \times 10^{3} / \mu \mathrm{L}$ (4-11), neutrophil count $6.5 \times 10^{3} / \mu \mathrm{L}(2.5-8.2)$, lymphocyte count $1.6 \times 10^{3} / \mu \mathrm{L}(1.5-5)$, and total platelet count $290 \times 10^{3} / \mu \mathrm{L}(150-450)$. It is important to highlight that his LDH levels were elevated (820 UI/L) [21].

\section{Diagnostic assessment and therapeutic intervention}

Our patient underwent a core-needle biopsy of the largest hepatic lesion in segment IVb without any complications. Pathology results were positive for MM and therefore the biopsy specimen was studied for mutations in BRAF, KIT, and NRAS genes using the cobas 4800 Test (cobas 4800 BRAF V600 Mutation Test; Roche Molecular Diagnostics, Inc., Pleasanton, CA, USA) and Sanger sequencing for the three genes. The V600R mutation was detected in the $B R A F$ gene (Fig. 1b); no mutations were detected in the KIT or NRAS genes. In August 2013, our patient was started on dabrafenib treatment in a compassionate-use program at the initial standard dose of $150 \mathrm{mg}$ orally every $12 \mathrm{~h}$.

\section{Follow-up and outcome}

Our patient's asthenia showed a rapid recovery, with rapid improvement in his ECOG score from 1 to 0 in the first month of treatment. In subsequent evaluations, only minimal cutaneous toxicity appeared (beard alopecia and the appearance of several milium cysts, see Fig. 1c). Several warty lesions appeared, none of them compatible with keratoacanthoma or cutaneous squamous-cell carcinoma.

His first radiological evaluation by CT, 2.5 months after starting treatment, showed a partial reduction of both the hepatic and pulmonary lesions, which was considered to indicate stable disease by Response Evaluation Criteria In Solid Tumors (RECIST) 1.1 criteria [22]. This radiologic response was maintained in a second $\mathrm{CT}$ evaluation after 5 months of therapy (Fig. 1d).

Seven months after the start of treatment, our patient presented with pneumonia and was admitted to our Oncology ward. During his stay at our hospital, a CT scan showed hepatic and retroperitoneal progression, as well as the appearance of pericardial and pleural effusions (Fig. 1e). Additionally, MRI detected multiple bilateral brain metastases (Fig. 1f). Treatment with dabrafenib was stopped. His brain lesions were considered unresectable, and our patient 


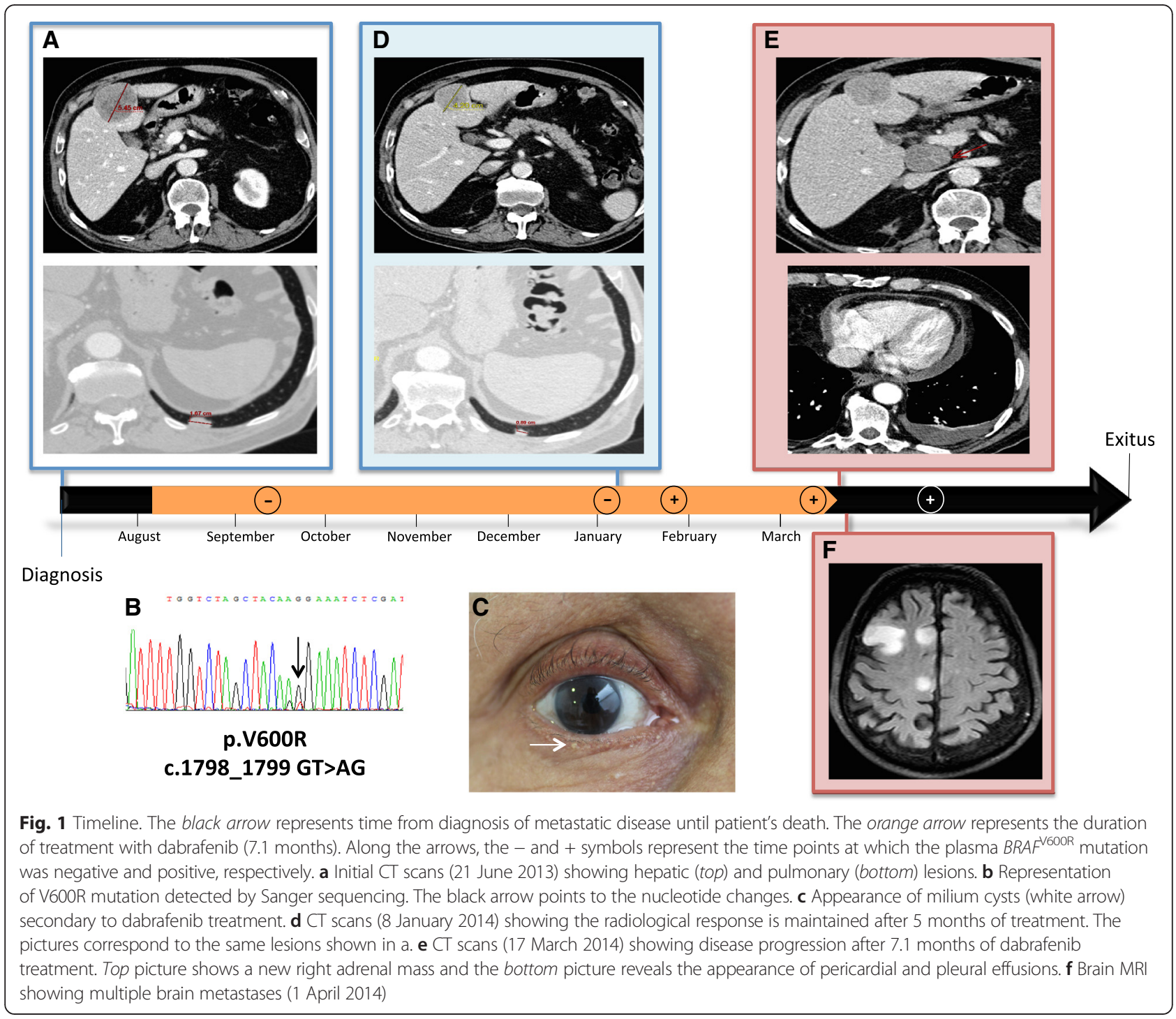

received whole brain radiotherapy. After this, he maintained an ECOG performance status of 2 and was thus deemed non-eligible for further treatments. He was referred to our palliative care unit and received regular in-home visits. Our patient died in September 2014.

\section{Exploratory ctDNA analysis}

As part of a research project at our center, plasma samples were periodically extracted during therapy. For this patient, five plasma samples were available for $B R A F$ mutation analysis. Plasma was obtained from $8 \mathrm{~mL}$ of peripheral blood collected in tubes with EDTA as the anticoagulant. The plasma was separated within $5 \mathrm{~h}$ by centrifugation at room temperature for $15 \mathrm{~min}$ at 3200 $\mathrm{rpm}$, then aliquoted and stored at $-80{ }^{\circ} \mathrm{C}$. ctDNA was extracted from the plasma using the QIAamp Circulating Nucleic Acid Kit (Qiagen, Hilden, Germany) according to the manufacturer's instructions. The $B R A F^{\mathrm{V} 600 \mathrm{R}}$ mutation was targeted in a real-time 7500 fast PCR (Life Technologies, Foster City, CA, USA) using a competitive allele-specific TaqMan (cast-PCR) assay specifically designed for this mutation (Life Technologies).

In the samples extracted on 13 September 2013 and 7 January 2014, the mutation was undetectable. In the samples extracted on 30 January and 13 March 2014 (the latter coinciding with the CT scan showing disease progression), the tumor's known $B R A F^{\mathrm{V} 600 \mathrm{R}}$ mutation was detected. The mutation was further detected in the samples extracted in April and May 2014.

\section{Discussion}

The $B R A F^{\mathrm{V} 600 \mathrm{R}}$ mutation occurs in up to $5 \%$ of MM cases and it results in the substitution of valine by arginine at amino acid 600 of the $B R A F$ gene. Similar to $B R A F^{\mathrm{V} 600 \mathrm{E}}$ and $B R A F^{\mathrm{V} 600 \mathrm{~K}}, B R A F^{\mathrm{V} 600 \mathrm{R}}$ causes an increase in $B R A F$ protein-kinase activity [13, 23]. Evidence regarding the 
clinical activity of BRAF inhibitors in patients with tumors harboring the $B R A F^{\mathrm{V} 600 \mathrm{R}}$ mutation is scarce and comes from case reports and series of cases. Klein et al. [18] have reported the largest series of patients with $B R A F^{\mathrm{V} 600 \mathrm{R}}$-mutant tumors treated with BRAF inhibitors. Five out of nine patients in this series showed a partial response and one patient was maintained for 10.4 months on dabrafenib treatment before showing disease progression. In the same year, van den Brom et al. [24] reported clinical activity of vemurafenib in a patient with a $B R A F^{\mathrm{V} 600 \mathrm{R}}$-mutated MM with a solitary brain metastasis. They observed a significant improvement in their patient's neurological symptoms and demonstrated a partial response of the brain lesion by RECIST criteria.

Our patient was evaluated as an 80-year-old man with an excellent quality of life, with an ECOG performance status of 1 with moderate comorbidity (age-adjusted Charlson Index of 8) and a poor prognosis according to total LDH levels [21]. At our institution, BRAF mutations are initially assessed through the cobas 4800 Test and all cases are further confirmed by Sanger sequencing. At the time of our patient's diagnosis, approval of dabrafenib or vemurafenib in Spain by the national regulatory agencies (AEMPS) was still pending. In our public health system, the only authorized first-line treatments were chemotherapeutic agents such as dacarbazine or fotemustine. Clinical benefits with chemotherapy are only seen in a limited number of patients. In the most recent trials in patients with $B R A F$-mutated MM being treated with dacarbazine in the control arm, response rates were around 5-10\% and progression-free survival (PFS) times were less than 2 months [7, 10, 25]. After discussing the benefits and risks of chemotherapy versus a targeted agent with the patient and his family, a decision was made for a targeted therapy. We were able to obtain dabrafenib in a compassionate-use protocol from GlaxoSmithKline. In the pivotal trial of dabrafenib [10], elderly patients were also included, and the maximum age was 93 in the experimental arm. Also, dabrafenib is mainly eliminated in the feces and thus needed no dose adjustment considering our patient's renal function.

As reported above, our patient's tolerance to the treatment was excellent, with minimal cutaneous toxicity. He stayed on the treatment for 7.1 months, which is above the median PFS observed in the BREAK-3 trial [10], and he lived for 15 months.

Non-BRAF ${ }^{\mathrm{V} 600 \mathrm{E}}$ mutations have been associated with increasing age, and clinical differences have been reported regarding the primary site of the tumor between $B R A F^{\mathrm{V} 600 \mathrm{E}}$ - and $B R A F^{\mathrm{V} 600 \mathrm{~K}}$-mutated MMs [26]. Interestingly, the nine $B R A F^{\mathrm{V} 600 \mathrm{R}}$-mutated MMs reported by Klein and collaborators [18] share some clinical features with our patient. Eight of their nine patients were men and four of them were older than 70 years. Primary lesions were in the scalp in four patients and were ulcerated in six of them. However, the numbers are too small to draw conclusions.

Finally, we performed an exploratory analysis of ctDNA as a biomarker during the targeted treatment. Although technical and economical limitations preclude us from using this method efficiently in our daily clinical practice, it shows great promise as a means for early diagnosis and tumor-burden monitoring [19, 27]. All our analyses were performed retrospectively within an investigational trial and were not used for treatment decisions. In our patient, the mutation was undetectable during dabrafenib treatment and response, becoming detectable before radiologically detected disease progression. Although it is tempting, no robust conclusions can be drawn from these observations, since we had no available plasma at the time of diagnosis and we did not explore other mutations apart from the $B R A F^{\mathrm{V} 600 \mathrm{R}}$. However, this finding is coherent with the knowledge that, in MM with acquired resistance to BRAF inhibitors, the original BRAF mutation persists [28].

\section{Conclusions}

This case report highlights (1) the benefits that can be obtained with a BRAF inhibitor in real-world patients with MM harboring the $B R A F^{\mathrm{V} 600 \mathrm{R}}$ mutation, and (2) the potential application of emerging new techniques such as ctDNA detection in our everyday clinical practice. In our opinion, the possibility of on-site molecular testing and the availability of targeted treatment greatly impacted our patient's outcome and quality of life.

Finally, patients with an MM harboring a $B R A F^{\mathrm{V} 600 \mathrm{R}} \mathrm{mu}-$ tation should not be excluded from randomized clinical trials (RCTs). This is of greatest importance in countries with a public health system, because local regulatory agencies strictly rely on RCT data to approve new treatments for the different subsets of patients.

\section{Abbreviations}

$A L T$, alanine aminotransferase; ASP, aspartate aminotransferase; $C T$, computed tomography; ctDNA, circulating tumor DNA; ECOG, Eastern Cooperative Oncology Group; ERK, extracellular signal-regulated kinases; GGT, gamma-glutamyltransferase; LDH, lactate dehydrogenase; MM, malignant melanoma; MRI, magnetic resonance imaging; PFS, progression-free survival; RAF, raf proto-oncogene;RAS, rat sarcoma oncogene; RCT, randomized controlled trial; MEK, mitogen-activated protein kinases / extracellular signal-regulated kinases

\section{Acknowledgements}

We would like to thank nurses Roser Correa Soler and Gemma Martínez Peña for performing the serial plasma extractions and for their continuous care for the patient. We also would like to thank Dr Edurne Arriola Aperribay, MD, $\mathrm{PhD}$, for critically reviewing the manuscript and for her valuable contributions.

\section{Authors' contributions}

DC and JV collected and assembled the clinical data. DC performed the extensive literature review and drafted the manuscript. FG diagnosed and 
followed the patient during treatment and provided the photograph included in the figure. FZ selected and provided images from the serial radiologic evaluations. $M A, A D$, and $B B$ processed the tumor biopsy and undertook its pathological and molecular analysis. AD and BB processed the plasma samples and performed serial ctDNA analyses. CM performed the outpatient management during treatment and the posterior follow-up, and coordinated the serial plasma extractions together with $\mathrm{JV}$. All authors reviewed and contributed to the final version of the manuscript. All authors read and approved the final manuscript.

\section{Competing interests}

The authors declare that they have no competing interests.

\section{Consent}

Written informed consent was obtained from the patient for publication of this case report and any accompanying images. A copy of the written consent is available for review by the Editor-in-Chief of this journal.

\section{Author details}

${ }^{1}$ Medical Oncology Department, Hospital del Mar, Passeig Marítim 25-29, 08003 Barcelona, Spain. ²Dermatology Department, Hospital del Mar, Barcelona, Spain. ${ }^{3}$ Radiology Department, Hospital del Mar, Barcelona, Spain. ${ }^{4}$ Pathology Department, Hospital del Mar, Barcelona, Spain. ${ }^{5}$ Cancer Research Program, IMIM (Hospital del Mar Medical Research Institute), Barcelona, Spain.

\section{Received: 6 January 2016 Accepted: 13 May 2016}

Published online: 02 June 2016

\section{References}

1. Dibb NJ, Dilworth SM, Mol CD. Switching on kinases: oncogenic activation of BRAF and the PDGFR family. Nat Rev Cancer. 2004;4(9):718-27.

2. Aoki $Y$, Niihori $T$, Inoue $S$, Matsubara $Y$. Recent advances in RASopathies. J Hum Genet. 2016;61(1):33-9.

3. Harmon CM, Brown N. Langerhans cell histiocytosis: a clinicopathologic review and molecular pathogenetic update. Arch Pathol Lab Med. 2015; 139(10):1211-4

4. Sarkozy A, Carta C, Moretti S, Zampino G, Digilio MC, Pantaleoni F, et al. Germline BRAF mutations in Noonan, LEOPARD, and cardiofaciocutaneous syndromes: molecular diversity and associated phenotypic spectrum. Hum Mutat. 2009;30(4):695-702.

5. Davies H, Bignell GR, Cox C, Stephens P, Edkins S, Clegg S, et al. Mutations of the BRAF gene in human cancer. Nature. 2002;417(6892):949-54.

6. Wan PT, Garnett MJ, Roe SM, Lee S, Niculescu-Duvaz D, Good VM, et al. Mechanism of activation of the RAF-ERK signaling pathway by oncogenic mutations of B-RAF. Cell. 2004;116(6):855-67.

7. Sosman JA, Kim KB, Schuchter L, Gonzalez R, Pavlick AC, Weber JS, et al. Survival in BRAF V600-mutant advanced melanoma treated with vemurafenib. N Engl J Med. 2012;366(8):707-14.

8. Greaves WO, Verma S, Patel KP, Davies MA, Barkoh BA, Galbincea JM, et al. Frequency and spectrum of BRAF mutations in a retrospective, singleinstitution study of 1112 cases of melanoma. J Mol Diagn. 2013;15(2):220-6.

9. Chapman PB, Hauschild A, Robert C, Haanen JB, Ascierto P, Larkin J, et al. Improved survival with vemurafenib in melanoma with BRAF V600E mutation. N Engl J Med. 2011;364(26):2507-16.

10. Hauschild A, Grob JJ, Demidov LV, Jouary T, Gutzmer R, Millward M, et al. Dabrafenib in BRAF-mutated metastatic melanoma: a multicentre, openlabel, phase 3 randomised controlled trial. Lancet. 2012;380(9839):358-65.

11. McArthur GA, Chapman PB, Robert C, Larkin J, Haanen JB, Dummer R, et al. Safety and efficacy of vemurafenib in BRAF(V600E) and BRAF(V600K) mutation-positive melanoma (BRIM-3): extended follow-up of a phase 3, randomised, open-label study. Lancet Oncol. 2014;15(3):323-32.

12. Ascierto PA, Minor D, Ribas A, Lebbe C, O'Hagan A, Arya N, et al. Phase II trial (BREAK-2) of the BRAF inhibitor dabrafenib (GSK2118436) in patients with metastatic melanoma. J Clin Oncol. 2013;31(26):3205-11.

13. Lovly CM, Dahlman KB, Fohn LE, Su Z, Dias-Santagata D, Hicks DJ, et al. Routine multiplex mutational profiling of melanomas enables enrollment in genotype-driven therapeutic trials. PLoS One. 2012;7(4):e35309.

14. Heinzerling L, Kuhnapfel S, Meckbach D, Baiter M, Kaempgen E, Keikavoussi $P$, et al. Rare BRAF mutations in melanoma patients: implications for molecular testing in clinical practice. Br J Cancer. 2013;108(10):2164-71.
15. Larkin J, Ascierto PA, Dreno B, Atkinson V, Liszkay G, Maio M, et al. Combined vemurafenib and cobimetinib in BRAF-mutated melanoma. N Engl J Med. 2014;371(20):1867-76.

16. Robert C, Karaszewska B, Schachter J, Rutkowski P, Mackiewicz A, Stroiakovski D, et al. Improved overall survival in melanoma with combined dabrafenib and trametinib. N Engl J Med. 2015;372(1):30-9.

17. Gentilcore G, Madonna G, Mozzillo N, Ribas A, Cossu A, Palmieri G, et al. Effect of dabrafenib on melanoma cell lines harbouring the BRAF(V600D/R) mutations. BMC Cancer. 2013;13:17.

18. Klein O, Clements A, Menzies AM, O'Toole S, Kefford RF, Long GV. BRAF inhibitor activity in V600R metastatic melanoma. Eur J Cancer. 2013;49(5):1073-9.

19. Diehl F, Schmidt K, Choti MA, Romans K, Goodman S, Li M, et al. Circulating mutant DNA to assess tumor dynamics. Nat Med. 2008;14(9):985-90.

20. Paek SC, Griffith KA, Johnson TM, Sondak VK, Wong SL, Chang AE, et al. The impact of factors beyond Breslow depth on predicting sentinel lymph node positivity in melanoma. Cancer. 2007;109(1):100-8.

21. Balch CM, Gershenwald JE, Soong SJ, Thompson JF, Atkins MB, Byrd DR, et al. Final version of 2009 AJCC melanoma staging and classification. J Clin Oncol. 2009;27(36):6199-206.

22. Eisenhauer EA, Therasse P, Bogaerts J, Schwartz LH, Sargent D, Ford R, et al. New response evaluation criteria in solid tumours: revised RECIST guideline (version 1.1). Eur J Cancer. 2009:45(2):228-47.

23. Houben R, Becker JC, Kappel A, Terheyden P, Brocker EB, Goetz R, et al. Constitutive activation of the Ras-Raf signaling pathway in metastatic melanoma is associated with poor prognosis. J Carcinog. 2004;3(1):6.

24. van den Brom RR, de Vries EG, Schroder CP, Hospers GA. Effect of vemurafenib on a V600R melanoma brain metastasis. Eur J Cancer. 2013; 49(7):1795-6.

25. Robert C, Schadendorf D, Messina M, Hodi FS, O'Day S. investigators MDX. Efficacy and safety of retreatment with ipilimumab in patients with pretreated advanced melanoma who progressed after initially achieving disease control. Clin Cancer Res. 2013;19(8):2232-9.

26. Menzies AM, Haydu LE, Visintin L, Carlino MS, Howle JR, Thompson JF, et al. Distinguishing clinicopathologic features of patients with V600E and V600K BRAF-mutant metastatic melanoma. Clin Cancer Res. 2012;18(12):3242-9.

27. Bettegowda C, Sausen M, Leary RJ, Kinde I, Wang Y, Agrawal N, et al. Detection of circulating tumor DNA in early- and late-stage human malignancies. Sci Transl Med. 2014;6(224):224ra224

28. Shi H, Hugo W, Kong X, Hong A, Koya RC, Moriceau G, et al. Acquired resistance and clonal evolution in melanoma during BRAF inhibitor therapy. Cancer Discovery. 2014;4(1):80-93.

\section{Submit your next manuscript to BioMed Central and we will help you at every step:}

- We accept pre-submission inquiries

- Our selector tool helps you to find the most relevant journal

- We provide round the clock customer support

- Convenient online submission

- Thorough peer review

- Inclusion in PubMed and all major indexing services

- Maximum visibility for your research

Submit your manuscript at www.biomedcentral.com/submit
) Biomed Central 